\title{
FORMULATION OF THE MATHEMATICAL MODEL TO MAXIMIZE THE TOTAL ANNUAL COST SAVINGS OF A POWER TRANSMISSION OR DISTRIBUTION SYSTEM
}

\author{
CRISTHIAN E. MOLINA C, ROBERTO POVEDA \& EDWIN RIVAS TRUJILLO
}

Facultad de Ingeniería, Universidad Distrital Francisco José de Caldas, Bogotá D.C., Colombia

\section{ABSTRACT}

In this article the authors propose a mixed integer non-linear programming algorithm (MINLP) to calculate the annual total cost savings (TCS) by optimizing the location and size, of Static Synchronous Compensators (STATCOMs) in transmission and distribution systems of electrical energy.

The MINLP algorithm is focused on minimizing the active power losses present in the system lines in order to maximize its annual TCS. The algorithm was implemented in the General Algebraic Modeling System (GAMS) software for the IEEE-33 radial distribution system, the results of which were compared with those presented by other authors. KEYWORDS: Optimization, Power Losses, STATCOM \& Total Cost Savings

Received: Oct 08, 2020; Accepted: Oct 28, 2020; Published: Nov 17, 2020; Paper Id.: IJMPERDOCT202053

\section{INTRODUCTION}

One of the methods that has emerged for the optimization of electrical power systems at the transmission and distribution levels is the inclusion of Flexible AC Transmission Systems (FACTS) in specific nodes of the network, which allow the reduction of losses caused by the Joule effect and improve the voltage profiles of the nodes near its connection.

The Static Synchronous Compensator (STATCOM) is a voltage source converter (VSC), which is part of the FACTS, connected in derivation with the transmission and distribution networks capable of regulating the voltage, compensating the reactive power and eliminating current harmonics. The STATCOM allows effective control of power exchanges with the system through the absorption or generation of controllable active and reactive power. [1]

The STATCOM is capable of injecting lagging or leading compensation current associated with a specific load, in order to comply with the technical specifications of the network. The optimal allocation of STATCOMs maximizes the load capacity, minimizes power losses, improves stability, compensates the reactive power and improves power quality. [2]

The authors propose a mathematical model to determine the economic benefit obtained from optimizing the inclusion of STATCOMs in electrical energy systems. The model offers a joint technical-economic solution that maximizes the annual TCS of the network through the minimization of active power losses.

\section{LITERATURE REVIEW}


In [3] the effect of the STATCOM to mitigate power losses and improve the voltage stability of a transmission system is investigated. They adopt the Newton Raphson algorithm to find the load flow before and after including the STATCOM within the system considering four different scenarios.

In [4] the problem of optimization in size and location for distributed generators (DG) in radial distribution networks is approached by presenting a MINLP.

In [5] the application of the Global Harmony Search Algorithm (GHS) for the optimal location and size of STATCOM in power systems is shown. They use the Newton Raphson method to calculate the load flow while the GHS is used to find the most suitable nodes for the STATCOM installation and their nominal power.

In [6] the optimal location and size of the Distribution Static Compensator (DSTATCOM) in order to reduce power losses and improve current and voltage profiles in distribution networks is exposed. For which an immunological algorithm to determine the best location and size of DSTATCOM is developed taking as parameters the voltage and current profiles, the minimum installation cost of DSTATCOM and the maximum reduction of power loss.

In [7] a new approach to find the optimal location and size of the Distribution Static Compensator (DSTATCOM) using the minimization of total network power losses as an objective function is presented. The GHS algorithm is used to find the optimal location and size of DSTATCOM.

\section{MATHEMATICAL MODEL}

In this section, the authors present the formulation of the mathematical model to determine the annual TCS in a transmission or distribution system that includes a STATCOM. The model has the following 4 stages:

- Determine the free power flow (FPF).

- Determine the optimal power flow (OPF).

- Locate and size the STATCOMs to include.

- Calculate the annual TCS for the system.

\subsection{FPF}

FPF is defined as the power flow presented by the system without the operational restrictions in voltage stability, and it is formulated in equations 1 (objective function) [4], 2 (active power balance at each node) and 3 (reactive power balance at each node) [8].

$$
\operatorname{Min} Z=\sum_{i=1}^{n} V i \sum_{j=1}^{n} V j * Y i j * \cos (\delta i-\delta j-\theta i j)(1)
$$

Subject to:

$$
\begin{aligned}
& P g_{i}-P d_{i}=V i \sum_{j=1}^{n} V j * Y i j * \cos (\delta i-\delta j-\theta i j) \\
& Q g_{i}-Q d_{i}=V i \sum_{j=1}^{n} V j * Y i j * \operatorname{sen}(\delta i-\delta j-\theta i j)
\end{aligned}
$$




\subsection{OPF}

OPF is a nonlinear optimization problem that represents the steady state operation of the electrical power system and allows determining the optimal value of the control variables considering the technical operating restrictions [8]. The objective of the OPF within the proposed model is to limit the dispersion in the magnitudes of the nodal voltages that the system presents.

To determine the OPF, a restriction must be added to the model proposed for the FPF as presented in equation 4 [4].

$$
V i^{\min } \leq V i \leq V i^{\max }(4)
$$

\subsection{STATCOMs}

In order to find the optimal location and dimensioning of the STATCOMs, the number of devices to be included in the system, a binary decision variable that will take the value of 1 if the STATCOM is located in the node and 0 if otherwise and the maximum value in $\mathrm{kVAr}$ that each device can take must be defined. The above should be included as restrictions to the model as presented in equations 5, 6 and 7 .

$$
\begin{gathered}
\# \text { \#TATCOMs } \leq \# \text { STATCOMs }{ }^{\max }(5) \\
X_{i} \leq \# S T A T C O M s^{\max }(6) \\
0 \leq Q_{g s} \leq X_{i} * Q_{g S}^{\max }(7)
\end{gathered}
$$

\subsection{TCS}

The quantification of the annual TCS that is achieved from the incorporation of STATCOMs in electrical energy transmission and distribution systems is obtained by using equations 8 (annual TCS), 9 (annual cost of STATCOM) [6] and 10 (STATCOM cost per dimensioning) [7].

$$
\begin{aligned}
& T C S=K_{P}\left(T * P_{\text {Losses }}^{\text {Without STATCOM }}\right)-K_{P}\left(T * P_{\text {Losses }}^{\text {With STATCOM }}\right)-K_{C} * \text { STATCOM } \text { Yearly cost }_{\text {(8) }} \\
& \operatorname{STATCOM}_{\text {Yearly Cost }}=\text { STATCOM }_{\text {Total Cost }} * \frac{(1+B)^{N_{\text {STATCOM }}} * B}{(1+B)^{N_{\text {STATCOM }}-1}}(9) \\
& \text { STATCOM }_{\text {Total } \text { cost }}=\operatorname{STATCOM}_{\text {Cost }} * Q_{g} S(10)
\end{aligned}
$$

\section{SYSTEM DESCRIPTION}

The IEEE-33 radial distribution system (Figure 1) is proposed as a case study, which has a base voltage of $12.66 \mathrm{kV}$ and power demand of $3715 \mathrm{~kW}$ and $2300 \mathrm{kVAr}$. The data associated with the transmission lines and loads discriminated by nodes are presented in Table 1. 


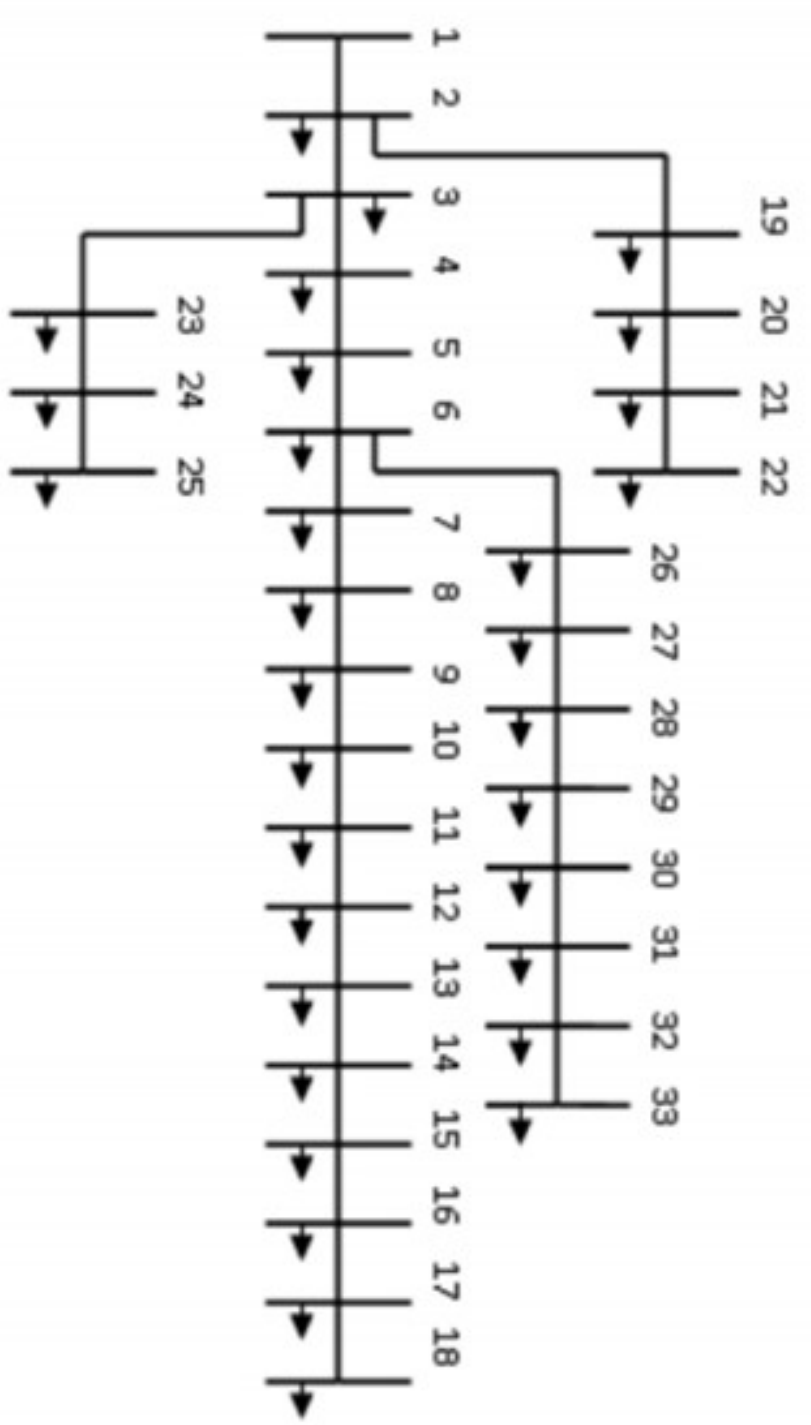

Figure 1: IEEE-33 radial distribution system. [9]

Table 1: IEEE-33 radial distribution system data. [10]

\begin{tabular}{|c|c|c|c|c|c|}
\hline Node i & Node $\mathbf{j}$ & $\mathbf{R}_{\mathrm{ij}}(\mathbf{\Omega})$ & $\mathbf{X}_{\mathbf{i j}}(\mathbf{\Omega})$ & $\mathbf{P}_{\mathbf{j}}(\mathbf{k W})$ & $\mathbf{Q}_{\mathbf{j}}(\mathbf{k V A r})$ \\
\hline 1 & 2 & 0,0922 & 0,0477 & 100 & 60 \\
\hline 2 & 3 & 0,4930 & 0,2511 & 90 & 40 \\
\hline 3 & 4 & 0,3660 & 0,1864 & 120 & 80 \\
\hline 4 & 5 & 0,3811 & 0,1941 & 60 & 30 \\
\hline 5 & 6 & 0,8190 & 0,7070 & 60 & 20 \\
\hline 6 & 7 & 0,1872 & 0,6188 & 200 & 100 \\
\hline 7 & 8 & 1,7114 & 1,2351 & 200 & 100 \\
\hline
\end{tabular}




\begin{tabular}{|c|c|c|c|c|c|}
\hline 8 & 9 & 1,0300 & 0,7400 & 60 & 20 \\
\hline 9 & 10 & 1,0400 & 0,7400 & 60 & 20 \\
\hline 10 & 11 & 0,1966 & 0,0650 & 45 & 30 \\
\hline 11 & 12 & 0,3744 & 0,1238 & 60 & 35 \\
\hline 12 & 13 & 1,4680 & 1,1550 & 60 & 35 \\
\hline 13 & 14 & 0,5416 & 0,7129 & 120 & 80 \\
\hline 14 & 15 & 0,5910 & 0,5260 & 60 & 10 \\
\hline 15 & 16 & 0,7463 & 0,5450 & 60 & 20 \\
\hline 16 & 17 & 1,2890 & 1,7210 & 60 & 20 \\
\hline 17 & 18 & 0,7320 & 0,5740 & 90 & 40 \\
\hline 2 & 19 & 0,1640 & 0,1565 & 90 & 40 \\
\hline 19 & 20 & 1,5042 & 1,3554 & 90 & 40 \\
\hline 20 & 21 & 0,4095 & 0,4784 & 90 & 40 \\
\hline 21 & 22 & \begin{tabular}{|l|}
0,7089 \\
\end{tabular} & 0,9373 & 90 & 40 \\
\hline 3 & 23 & 0,4512 & 0,3083 & 90 & 50 \\
\hline 23 & 24 & 0,8980 & 0,7091 & 420 & 200 \\
\hline 24 & 25 & 0,8960 & 0,7011 & 420 & 200 \\
\hline 6 & 26 & 0,2030 & 0,1034 & 60 & 25 \\
\hline 26 & 27 & 0,2842 & 0,1447 & 60 & 25 \\
\hline 27 & 28 & 1,0590 & 0,9337 & 60 & 20 \\
\hline 28 & 29 & 0,8042 & 0,7006 & 120 & 70 \\
\hline 29 & 30 & 0,5075 & 0,2585 & 200 & 600 \\
\hline 30 & 31 & 0,9744 & 0,9630 & 150 & 70 \\
\hline 31 & 32 & 0,3105 & 0,3619 & 210 & 100 \\
\hline 32 & 33 & 0,3410 & 0,5302 & 60 & 40 \\
\hline
\end{tabular}

\section{RESULTS}

The proposed mathematical model was implemented in GAMS, through the KNITRO solver, applied to the IEEE-33 radial distribution system.

For the implemented system, the dispersion limits of the nodal voltages in pu, the maximum number of 
STATCOMs, their maximum size in $\mathrm{kVAr}$ and the parameters $\mathrm{K}_{\mathrm{P}}, \mathrm{T}, \mathrm{KC}$, ST ATCOM $_{\text {Cost }}$, B, and $\mathrm{N}^{\mathrm{STATCOM}}$ were defined with the same values used in [6] and [7] and are presented in Tables 2 and 3.

Table 2: Restrictions for the OPF and STATCOMs

\begin{tabular}{|l|l|l|}
\hline Voltage limits & Number of decives & Maximum size of devices \\
\hline $0.90 \leq \mathrm{V}_{\mathrm{i}} \leq 1.10$ & \#STATCOMs $^{\max }=1$ & $\mathrm{Q}_{\mathrm{gs}}{ }^{\max }=10000 \mathrm{kVAr}$ \\
\hline
\end{tabular}

Table 3: Parameter values to calculate the annual TCS

\begin{tabular}{|c|c|c|c|c|c|}
\hline $\mathbf{K}_{\mathbf{P}} \mathbf{( \$ / k W h )}$ & $\mathbf{T}$ & $\mathbf{K}_{\mathbf{C}}$ & $\mathbf{S T A T C O M}_{\text {Cost }} \mathbf{( \$ / k V A r )}$ & $\mathbf{B}$ & $\mathbf{N}^{\text {STATCOM }}$ (Years) \\
\hline 0,06 & 8760 & 1 & 50 & 0,1 & 30 \\
\hline
\end{tabular}

A STATCOM (Table 4) was located and sized, in such a way that the annual TCS of the network was maximized from the minimization of active power losses. The results obtained were compared with those presented in [6] and [7].

Table 4: Optimal location and sizing of the STATCOM

\begin{tabular}{|l|l|l|}
\hline & \multicolumn{2}{|l|}{ STATCOM } \\
\hline Node & Location & Size (kVAr) \\
\hline 30 & 1 & 1258 \\
\hline
\end{tabular}

Table 5 presents the power losses before and after the inclusion of the STATCOM, achieving a reduction in active and reactive power losses of $28.26 \%$ and $27.41 \%$ respectively.

Table 5: Losses with and without STATCOM

\begin{tabular}{|l|l|l|l|l|}
\hline & \multicolumn{2}{|l|}{ Without STATCOM } & \multicolumn{2}{l|}{ With STATCOM } \\
\hline & P (kW) & Q (kVAr) & P (kW) & Q (kVAr) \\
\hline Losses & 210,98 & 143,12 & 151,36 & 103,89 \\
\hline Reduction & NA & NA & $28.26 \%$ & $27.41 \%$ \\
\hline
\end{tabular}

Table 6 compares the active and reactive power losses, the optimal location and sizing of the STACOM, as well as the annual TCS for the methods presented in [6] and [7] and the model proposed by the authors. 
Table 6: Comparison of results

\begin{tabular}{|l|l|l|l|l|l|}
\hline & \multicolumn{2}{|c|}{ Base Case } & \multicolumn{1}{|c|}{$[6]$} & {$[7]$} & Proposed Model \\
\hline Size (kVAr) & NA & NA & 962.49 & 1150 & 1258 \\
\hline Location (Node) & NA & NA & 12 & 30 & 30 \\
\hline Plosses (kW) & 202.67 & 210.98 & 171.79 & 143.97 & 151.36 \\
\hline$Q_{\text {lossess (kVAr) }}$ & 135.24 & 143.12 & 115.26 & 96.47 & 103.89 \\
\hline$V_{\min }(\mathbf{p u})$ & 0.9131 & 0.9038 & 0.9258 & 0.9236 & 0.9165 \\
\hline Annual TCS (\$) & NA & NA & $\mathbf{1 1 1 3 0}$ & $\mathbf{2 4 2 6 4}$ & $\mathbf{2 4 6 6 4}$ \\
\hline
\end{tabular}

In [6] and [7] power losses of $202.67 \mathrm{~kW}$ and $135.24 \mathrm{kVAr}$ are presented, which differ from those actually obtained for the base case of the IEEE-33 network (210.98 kW and $143.12 \mathrm{kVAr})$. Therefore, Table 6 shows two columns for the Base Case, the first shows the values used in [6] and [7] and the second the values used by the model proposed by the authors.

When the STATCOM is included in node 30 of the IEEE-33 radial distribution system, a correction is generated in the magnitude of the system voltages, since shunt compensation produces an injection of current towards the node supplying the demand current of the load, reducing the voltage drop and therefore improving the voltage profile (Figure 2).

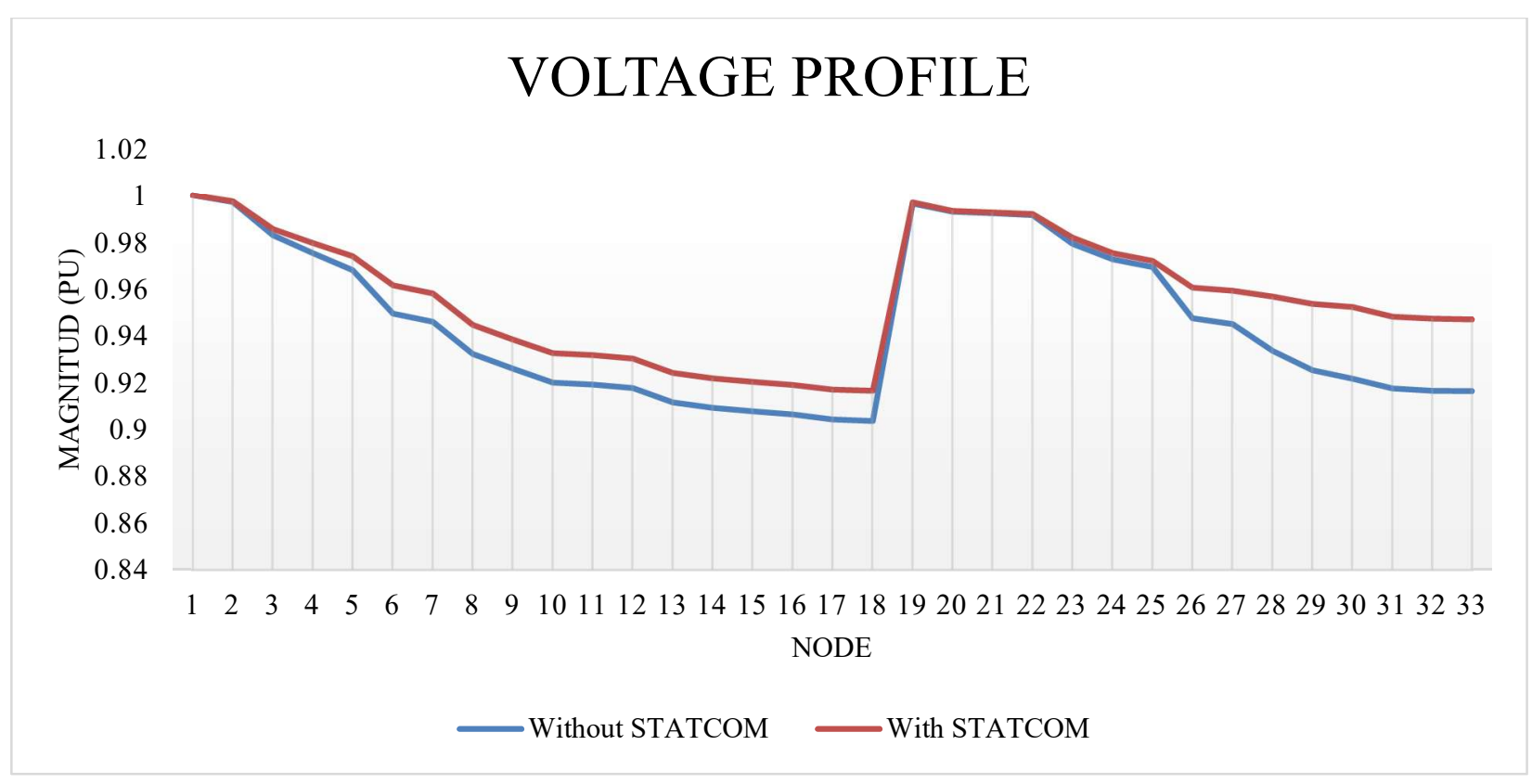

Figure 2: System voltage profile with and without the inclusion of the STATCOM.

In Figure 3 an overlap of the graphs corresponding to the voltage profile obtained with the model shown and the algorithms proposed in [6] and [7] is presented.

The inclusion of the STATCOM in node $12[6]$ allows to achieve an average correction of the voltage profile, 
between nodes $8-18$, which is $1.25 \%$ and $2 \%$ higher than that obtained in [7] and with MINLP respectively. On the other hand, the inclusion of the STATCOM in node 30 (MINLP) allows to achieve an average correction of the voltage profile, between nodes $26-33$, which is $1.58 \%$ and $0.2 \%$ higher than that obtained in [6] and [7] respectively.

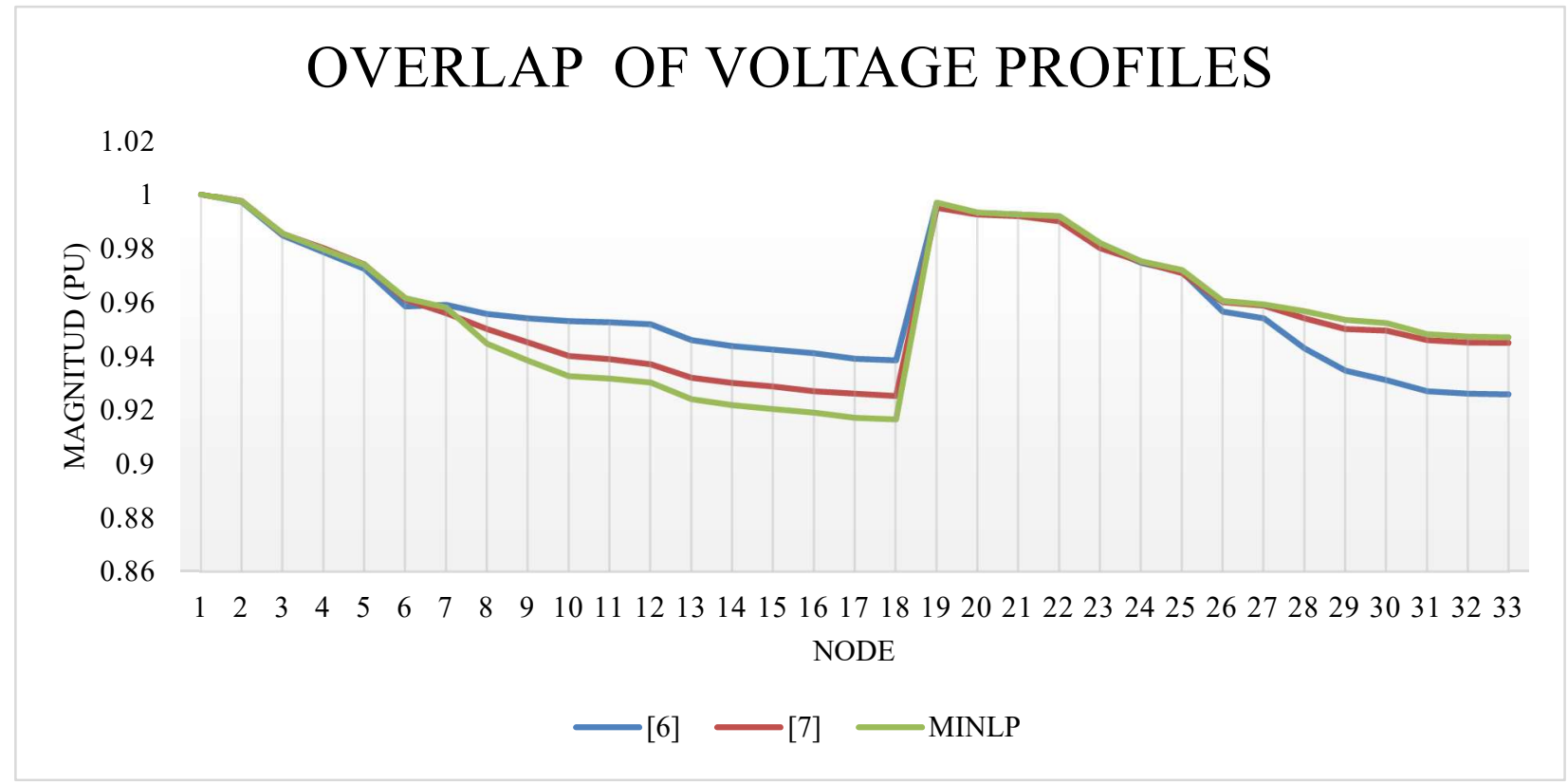

Figure 3: Overlap of voltage profiles.

\section{CONCLUSIONS}

The proposed mixed-integer nonlinear programming algorithm (MINLP) offers an alternative technical-economic solution for the optimal inclusion of STATCOMs in electrical power transmission and distribution systems, maximizing the annual TCS of the network through the minimization of active power losses.

The proposed MINLP algorithm allows a cost reduction of $121.6 \%$ and $1.65 \%$ in relation to that achieved with the algorithms proposed in [6] and [7] respectively.

\section{REFERENCES}

1. V. M. Awasth and V. A. Huchche, "Reactive power compensation using D-STATCOM," 2016 Int. Conf. Energy Effic. Technol. Sustain. ICEETS 2016, pp. 583-585, 2016, doi: 10.1109/ICEETS.2016.7583821.

2. I. Wasiak, R. Mienski, R. Pawelek, and P. Gburczyk, "Application of DSTATCOM compensators for mitigation of power quality disturbances in low voltage grid with distributed generation," 2007 9th Int. Conf. Electr. Power Qual. Util. EPQU, no. 11239, 2007, doi: 10.1109/EPQU.2007.4424166.

3. A. A. Adebiyi and K. T. Akindeji, "Investigating the Effect of Static Synchronous Compensator ( STATCOM) for Voltage Enhancement and Transmission Line Losses Mitigation," pp. 462-467, 2017.

4. O. Danilo, W. Gil-gonzález, and L. F. Grisales-noreña, "An exact MINLP model for optimal location and sizing of DGs in distribution networks : A general algebraic modeling system approach," Ain Shams Eng. J., vol. 11, no. 2, pp. 409-418, 2020, doi: 10.1016/j.asej.2019.08.011.

5. M. Koltun, “Optimal Placement and Sizing of STATCOMs in Power Systems using GHS Algorithm,” 2017. 
6. S. A. Taher and S. A. Afsari, "Optimal location and sizing of DSTATCOM in distribution systems by immune algorithm," Int. J. Electr. Power Energy Syst., vol. 60, pp. 34-44, 2014, doi: 10.1016/j.ijepes.2014.02.020.

7. T. Yuvaraj, K. R. Devabalaji, and K. Ravi, Optimal Placement and Sizing of DSTATCOM Using Harmony Search Algorithm, vol. 79. Elsevier B.V., 2015.

8. F. De Potencia, E. D. V. Vsc-opf, M. A. Ríos, C. J. Zapata, and O. Gómez, "Flujo de Potencia Óptimo con Restricciones de Estabilidad de Voltaje (VSC-OPF)," pp. 1-8.

9. P. S. Meera and S. Hemamalini, "Optimal Siting of Distributed Generators in a Distribution Network using Artificial Immune System," vol. 7, no. 2, pp. 641-649, 2017, doi: 10.11591/ijece.v7i2.pp641-649.

10. B. Venkatesh and R. Ranjan, "Optimal radial distribution system reconfiguration using fuzzy adaptation of evolutionary programming," vol. 25, pp. 775-780, 2003, doi: 10.1016/S0142- 0615(03)00046-2.

\section{ABBREVIATIONS}

Z

Pgi

$\mathrm{Pd}$

Qgi

Qdi

$\mathrm{Vi}$

$\mathrm{Vj}$

$\delta i$

$\delta j$

Yij

$\theta i j$

$V i^{\min }$

$V i^{\max }$

\#STATCOMs ${ }^{\text {max }}$

$\mathrm{X}_{\mathrm{i}}$

$\mathrm{QgS}^{\max }$

QgS

$\mathrm{K}_{\mathrm{P}}$

$\mathrm{T}$

$P_{\text {Losses }}^{\text {Without ST ATCOM }}$
Active power that is lost through the lines.

Active power generated at node i.

Active power demanded at node $\mathrm{i}$.

Reactive power generated at node $\mathrm{i}$.

Reactive power demanded at node $\mathrm{i}$.

Voltage magnitude of node $\mathrm{i}$.

Voltage magnitude of node $\mathrm{j}$.

Voltage angle of node i.

Voltage angle of node $\mathrm{j}$.

Magnitude of admittance between nodes $\mathrm{i}-\mathrm{j}$.

Admittance angle between nodes $\mathrm{i}-\mathrm{j}$.

Lower limit of the nodal voltages.

Upper limit of nodal voltages.

Limit of devices to locate.

Binary decision variable.

Maximum reactive power with which the STATCOM can be dimensioned.

Optimum reactive power of the STATCOM.

Cost of energy losses.

Total hours per year.

Active power lost before STATCOM installation. 
$P_{\text {LOSSES }}^{\text {With STCOM }}$

$\mathrm{K}_{\mathrm{C}}$

STATCOM Yearly Cost

STATCOM $M_{\text {Total Cost }}$

B

$\mathrm{N}^{\text {STATCOM }}$
Power lost after STATCOM installation.

Time duration ratio.

Annual cost of running the device.

Device sizing cost.

Asset rate of return.

Longevity of STATCOM. 